Research Article

\title{
Single-Stage Microwave-Assisted Coconut-Shell-Based Activated Carbon for Removal of Dichlorodiphenyltrichloroethane (DDT) from Aqueous Solution: Optimization and Batch Studies
}

\author{
Azrina Aziz $\mathbb{D}^{1},{ }^{1}$ Mohamad Nasran Nasehir Khan $\left(\mathbb{D},{ }^{1}\right.$ \\ Mohamad Firdaus Mohamad Yusop $\mathbb{D},{ }^{1}$ Erniza Mohd Johan Jaya $\mathbb{D}^{\mathbb{D}},{ }^{1}$ \\ Muhammad Azan Tamar Jaya $\mathbb{D}^{2},{ }^{2}$ and Mohd Azmier Ahmad ${ }^{1}$ \\ ${ }^{1}$ School of Chemical Engineering, Engineering Campus, Universiti Sains Malaysia, Nibong Tebal 14300, Penang, Malaysia \\ ${ }^{2}$ Kolej GENIUS Insan, Universiti Sains Islam Malaysia, Nilai 71800, Negeri Sembilan, Malaysia
}

Correspondence should be addressed to Mohd Azmier Ahmad; chazmier@usm.my

Received 8 July 2021; Revised 2 September 2021; Accepted 20 September 2021; Published 8 October 2021

Academic Editor: Sébastien Déon

Copyright (c) 2021 Azrina Aziz et al. This is an open access article distributed under the Creative Commons Attribution License, which permits unrestricted use, distribution, and reproduction in any medium, provided the original work is properly cited.

\begin{abstract}
This research aims to optimize preparation conditions of coconut-shell-based activated carbon (CSAC) and to evaluate its adsorption performance in removing POP of dichlorodiphenyltrichloroethane (DDT). The CSAC was prepared by activating the coconut shell via single-stage microwave heating under carbon dioxide, $\mathrm{CO}_{2}$ flow. The total pore volume, $\mathrm{BET}$ surface area, and average pore diameter of CSAC were $0.420 \mathrm{~cm}^{3} / \mathrm{g}, 625.61 \mathrm{~m}^{2} / \mathrm{g}$, and $4.55 \mathrm{~nm}$, respectively. The surface of CSAC was negatively charged shown by the zeta potential study. Response surface methodology (RSM) revealed that the optimum preparation conditions in preparing CSAC were $502 \mathrm{~W}$ and $6 \mathrm{~min}$ for radiation power and radiation time, respectively, which corresponded to $84.83 \%$ of DDT removal and $37.91 \%$ of CSAC's yield. Adsorption uptakes of DDT were found to increase with an increase in their initial concentration. Isotherm study revealed that DDT-CSAC adsorption system was best described by the Langmuir model with monolayer adsorption capacity, $Q_{m}$ of $14.51 \mathrm{mg} / \mathrm{g}$. The kinetic study confirmed that the pseudo-second-order model fitted well with this adsorption system. In regeneration studies, the adsorption efficiency had slightly dropped from $100 \%$ to $83 \%$ after 5 cycles. CSAC was found to be economically feasible for commercialization owing to its low production cost and high adsorption capacity.
\end{abstract}

\section{Introduction}

The global awareness of the threat of toxicity that comes from persistent organic pollutants (POPs) had led to the ban of their usage since the past 40 years ago [1]. POPs can be defined as a group of compounds which is synthetically produced having a high strain on the environment. Since they are significantly resistant to chemicals, they can resist breaking down for many years and continuously exist in the environment [2]. POPs can be recognized based on three main characteristics: (i) be high in toxicity, (ii) persistently bioaccumulate in the organisms' fatty tissue, thus moving to the food chain, and (iii) have the ability to be transferred over long distances in the forms of gaseous or particulate matter [3]. According to Guo et al. [4], there are three main groups under POPs. The first group is pesticides, mainly organochlorine pesticides (OCPs) like dichlorodiphenyltrichloroethane (DDT) and its metabolites. The second group is industrial and technical chemicals such as polychlorinated biphenyls (PCBs), perfluorooctanesulfonate (PFOS), and polybrominated diphenyl ethers (PBDEs). The last group is polychlorinated dibenzo-p-dioxins (PCDDs), polyaromatic hydrocarbons (PAHs), and polychlorinated dibenzofurans (PCDFs) which are formed as byproducts in industrial processes. DDT is one of the most popular pesticides used to increase crop production by killing unwelcomed pests. Unfortunately, serious health effects are observed to be associated with DDT such as nervous system dysfunction [5], endocrine disorder [6], dysfunction of the immune system [7], toxic effect on the reproductive system 
[8], and carcinogenic properties [9]. DDT has been traced in numerous types of foods, namely fish, milk, poultry, vegetables, fruits, cereals, and flour [10].

Some methods developed to treat wastewater containing DDT and other types of POPs were mechanochemical ball milling [11], bioremediation [12], electrokinetic remediation [3], and electrocoagulation [13]. Alas, these methods are restricted by extensive energy demand, the high cost of chemicals, and the development of secondary pollution. The adsorption process by using activated carbon (AC) as an adsorbent is seen as one of the best methods to treat wastewater containing POPs. Based on its ability to adsorb a wide range of pollutants, AC is also best known as a universal adsorbent. Several works done by researchers proved that AC is extremely versatile in removing pollutants such as cationic dyes [14, 15], anionic dyes [16, 17], heavy metals [18], phenolic compound [19], antibiotic [20], painkiller [21], carbon dioxide, $\mathrm{CO}_{2}$ gas [22], hydrogen sulfide, $\mathrm{H}_{2} \mathrm{~S}$ gas [23], and many others. Nevertheless, the application of AC is limited by the expensive cost of the precursors or starting materials. Because of that, for the past decade, researchers are actively converting lignocellulosic materials into AC including durian peel [14], peanut shell [24], corncob [18], meranti wood [25], pomegranate peel [26], Glyricidia sepium [27], acacia sawdust [28], durian seed [29], and others. The majority of these materials are wastes from agricultural activities which can be obtained in a large quantity, have continuous supply over the year, and are low in cost. Southeast Asian countries like Malaysia, Indonesia, Thailand, Myanmar, and Vietnam can gain economic benefit by converting these unwanted agricultural wastes into AC, besides solving the disposal problem of these wastes.

The complex connection between variables and responses which usually follows nonlinear theoretical models can figure out using computational intelligence methods [30]. Two of the most reliable computational intelligence methods are the fuzzy logic model (FLM) and response surface methodology (RSM). RSM was successfully implemented in many research due to its ability to evaluate multiple variables at once at a minimal number of experiments. Furthermore, other benefits of RSM include the ability to analyze the interaction effect between variables, generating three-dimensional (3D) graphs to relate variables and responses, and, last but not least, analysis of variance (ANOVA) is available to validate the results. In this study, an attempt was carried out to convert coconut shell into AC (CSAC) via microwave irradiation technique to adsorb DDT. RSM was employed to obtain optimum preparation conditions of radiation power and radiation time, which resulted in optimum DDT removal and CSAC's yield. To the best of the authors' knowledge, no work on optimizing microwave-induced-CSAC via RSM in adsorbing DDT has been reported in the literature.

\section{Materials and Methods}

2.1. Materials. The coconut shell was obtained from a local market in Nibong Tebal, Pulau Pinang. Once received, the raw coconut shell was washed thoroughly with water and dried in an oven for 24 hours at a temperature of $110^{\circ} \mathrm{C}$. Then, the dried coconut shell was ground into smaller pieces between the size of 0.5 and $1 \mathrm{~mm}$. Nitrogen, $\mathrm{N}_{2}$ gas, and carbon dioxide, $\mathrm{CO}_{2}$ gas, utilized during carbonization and activation processes were obtained from MOX Gases Berhad, Malaysia. DDT was supplied from Modern Lab Sdn. Bhd.

2.1.1. Preparation of CSAC. The dried coconut shell was subjected to an activation process via the microwave irradiation technique. $50 \mathrm{~g}$ of char was loaded inside a Pyrex glass tube and, then, placed inside the microwave's chamber. The microwave was turned on at different radiation power levels of 364, 490, and $616 \mathrm{~W}$ att and different radiation times of 2, 4, and 6 minutes. During this activation process, $\mathrm{CO}_{2}$ has flowed through the microwave at a flowrate of $150 \mathrm{~cm}^{3} /$ min. $\mathrm{CO}_{2}$ was crucial at this stage to provide a gasification effect on the sample, thus enhancing the development of the pore on the sample. The resulted product at the end of this process is called CSAC. The yield of CSAC was calculated using the following equation:

$$
\text { yield }=\frac{W_{f}}{W_{i}} \times 100 \%,
$$

where $W_{f}$ and $W_{i}$ are the weight of CSAC and dried weight of coconut shell, respectively.

2.1.2. Sample Analysis System. The Agilent 1260 HighPerformance Liquid Chromatography (HPLC), Eclipse C-18 column was used to identify the concentration of DDT in the water solution. In this method, the liquid samples were pump in a solvent known as the mobile phase at high pressure through a separation column. The separation column is a stationary phase consisting of packing materials made of densely packed, often chemically functionalized beads. The difference in the analyte's affinity for the solvent (mobile phase) and stationary phase enables separation to occur. The detection wavelength was set at $238 \mathrm{~nm}$.

2.1.3. Characterization Methods. Characterization of CSAC was made in terms of surface area, pore characteristic, surface morphology, proximate analysis, surface chemistry, and zeta potential. The surface area, pore volume, and average pore diameter of samples were determined by using a volumetric adsorption analyzer (Model: Micromeritics ASAP 2020), which was based on nitrogen gas adsorption at $77 \mathrm{~K}$. The surface area was measured from adsorption isotherm using Brunauer-Emmett-Teller (BET) equation. Total pore volume was estimated to be the liquid volume of nitrogen at a relative pressure of 0.99 . The surface morphology of samples was examined using a scanning electron microscope (SEM) ((Model: LEO SUPRA 55VP, Germany). Proximate analysis of the sample was carried out using STA (Model Perkin Elmer STA 6000, USA). From the STA result, the moisture, volatile matter, fixed carbon, and ash contents can be obtained by considering the weight of the sample as $100 \%$. The chemical characteristics of the surface functional 
group of CSAC were detected by mixing the AC sample in $\mathrm{K}-\mathrm{Br}$ pellets recorded with Fourier transform infrared (FTIR) spectroscope (Model: IR Prestige 21 Shimadzu, Japan) in $400-4000 \mathrm{~cm}^{-1}$ wavenumber range. The zeta potential of CSAC was determined using a zeta potential analyzer (Zetasizer Nano Series DKSH).

2.2. Experimental Design. Another aim in this research was to optimize the conditions in preparing CSAC by utilizing a standard RSM design called Central Composite Design (CCD). Software known as Design Expert (STAT-EASE Inc., Minneapolis, USA) version 6.0.6 was used to fulfill the optimization purpose. Radiation power $\left(X_{1}\right)$ and radiation time $\left(X_{2}\right)$ were selected as the variables whereas DDT removal $\left(Y_{1}\right)$ and CSAC's yield $\left(Y_{2}\right)$ were chosen as responses. Table 1 presents the variables and responses, together with experimental ranges and levels. Since 2 variables were studied, a design matrix with 13 experiments was generated which comprised 5 factorial points, 3 axial points, and 5 replicates. The replication was fruitful in determining the error of experiments. The quadratic model developed by RSM was expressed as follows:

$$
Y=\left(b_{o}+\varepsilon\right)+\sum_{i=1}^{3} b_{i} x_{i}+\sum_{i=1}^{3} b_{i i} x_{i}^{2}+\sum_{i=1}^{3} \sum_{j=i+1}^{3} b_{i j} x_{i} x_{j}+e_{i}
$$

where $Y$ is the predicted response; $b_{0}, b_{i}, b_{i j}$, and $b_{i i}$ are the constant coefficient, linear coefficient, interaction coefficient, and quadratic coefficient, respectively; $x_{i}$ and $x_{j}$ are the coded values of the AWAC preparation variables; and $e_{i}$ is the error. The adsorption process was conducted by placing $200 \mathrm{~mL}$ of DDT solution with an initial concentration of $20 \mathrm{mg} / \mathrm{L}$ into 13 conical flasks. These conical flasks were assembled inside a water bath shaker and accurately weighed $0.2 \mathrm{~g}$ of CSAC was added into each flask. The speed and temperature of the water bath shaker were fixed at $150 \mathrm{rpm}$ and $30^{\circ} \mathrm{C}$, respectively.

2.3. Equilibrium Study. The equilibrium study was conducted to understand the effect of different initial concentrations and contact time on the adsorption uptakes and percentage removal of DDT. $200 \mathrm{~mL}$ of this adsorbate at initial concentrations of $5,10,15$, and $20 \mathrm{mg} / \mathrm{L}$ were prepared in an Erlenmeyer flask. Then, $0.2 \mathrm{~g}$ of CSAC was added to each of these flasks. After that, these Erlenmeyer flasks were loaded inside a water bath shaker for the adsorption process to take place for $24 \mathrm{~h}$. The speed of agitation was fixed at $150 \mathrm{rpm}$ and the temperature of the water bath shaker was set at $30^{\circ} \mathrm{C}$. DDT solution was altered to have $\mathrm{pH}$ 7 using $0.1 \mathrm{M} \mathrm{NaOH}$. This $\mathrm{pH}$ was chosen to avoid the existence of excess $\mathrm{H}^{+}$or $\mathrm{OH}^{-}$ions in adsorbate solution from inducing the surface area of CSAC, thus affecting its adsorption capacity. This research was interested to verify the potential of CSAC's adsorption capacity at a neutral state. The following equations were utilized to determine adsorption uptakes and percentage removal of adsorbates, respectively:
TABLE 1: Experimental variables and levels.

\begin{tabular}{|c|c|c|c|c|c|c|}
\hline & & \multirow{2}{*}{ Unit } & \multirow{2}{*}{ Notation } & \multicolumn{3}{|c|}{ Coded values } \\
\hline & & & & -1 & 0 & +1 \\
\hline \multirow{2}{*}{ Variables } & $\begin{array}{l}\text { Radiation } \\
\text { power }\end{array}$ & Watt (W) & $X_{1}$ & 2.00 & 4.00 & 6.00 \\
\hline & $\begin{array}{l}\text { Radiation } \\
\text { time }\end{array}$ & $\begin{array}{l}\text { Minutes } \\
\quad(\min )\end{array}$ & $X_{2}$ & 364 & 490 & 616 \\
\hline \multirow{2}{*}{ Responses } & $\begin{array}{c}\text { DDT } \\
\text { removal }\end{array}$ & $\%$ & $Y_{1}$ & & - & \\
\hline & $\begin{array}{l}\text { CSAC's } \\
\text { yield }\end{array}$ & $\%$ & $Y_{2}$ & & - & \\
\hline
\end{tabular}

$$
\begin{aligned}
q_{e} & =\frac{\left(C_{o}-C_{e}\right) V}{M}, \\
\operatorname{removal}(\%) & =\frac{\left(C_{o}-C_{e}\right)}{C_{o}} \times 100 \%,
\end{aligned}
$$

where $q_{e}$ is the amount of adsorbate adsorbed by an adsorbent at equilibrium $(\mathrm{mg} / \mathrm{g}), C_{o}$ is the initial concentration of adsorbate solution $(\mathrm{mg} / \mathrm{L}), C_{e}$ is the concentration of adsorbate solution at equilibrium $(\mathrm{mg} / \mathrm{L}), V$ is the volume of solution ( $\mathrm{mL}$ ), and $M$ is the mass of adsorbent used $(\mathrm{g})$.

The study of adsorption isotherm was carried out by fitting the experimental equilibrium data onto three isotherm models namely Langmuir, Freundlich, and Temkin. The suitability of the isotherm equations in fitting the equilibrium data was evaluated by making a comparison between the correlation coefficients, $R^{2}$ value. The model which has a better agreement with the adsorption equilibrium data has an $R^{2}$ value approaching unity, indicating that the model was fitted well. These isotherm equations are as follows:

Langmuir [31] equation is as follows:

$$
q_{e}=\frac{Q_{m} K_{L} C_{e}}{1+K_{L} C_{e}}
$$

Freundlich [32] equation is as follows:

$$
q_{e}=K_{F} C_{e}^{1 / n_{F}}
$$

Temkin [33] equation is as follows:

$$
q_{e}=\frac{R T}{B} \ln \left(A C_{e}\right) \text {. }
$$

Here, $Q_{m}$ is maximum adsorption capacity; $K_{L}$ is the constant of Langmuir; $K_{F}$ and $n_{F}$ are constants of Freundlich; $B$ and $A$ are constants of Temkin, $R$ is the universal gas constant, and $T$ is the temperature.

2.4. Kinetic Study. The method of evaluation of batch kinetic studies was identical to the batch equilibrium experiments. The aqueous adsorbate samples of each respective flask were withdrawn at predetermined time intervals ranging from 15 to $180 \mathrm{~min}$. Adsorbate solutions with four different initial concentrations of $5,10,15$, and $20 \mathrm{mg} / \mathrm{L}$ were used. CSAC's mass, the volume of solution, the temperature of the solution, and the agitation speed of the water bath shaker were 
set to be $0.2 \mathrm{~g}, 200 \mathrm{~mL}, 30^{\circ} \mathrm{C}$, and $150 \mathrm{rpm}$, respectively. Kinetic models of pseudo-first-order and pseudo-secondorder were used to fit the kinetic data and their equations are given as follows.

Pseudo-first-order (PFO) [34] is as follows:

$$
q_{t}=q_{e}\left[1-\exp \left(-k_{1} t\right)\right] .
$$

Pseudo-second-order (PSO) [35] is as follows:

$$
q_{t}=\frac{k_{2} q_{e}^{2} t}{1+k_{2} q_{e} t} .
$$

Besides comparing the correlation factor $R^{2}$ to find the best model that fits kinetics data, the normalized standard deviation was used too. Normalized standard deviation measured the variance between experimental data and data obtained using the kinetics model equation. The model that fitted the kinetics data the best yielded a low value of normalized standard deviation. The equation used to find normalized standard deviation is as follows:

$$
\Delta q_{t}(\%)=100 \sqrt{\frac{\sum\left[\left(q_{t, \exp }-q_{t, \mathrm{cal}}\right) / q_{t, \mathrm{cal}}\right]^{2}}{(n-1)}},
$$

where $q_{t, \exp }$ is the measured amount of adsorbate adsorbed at the time, $q_{t, \text { cal }}$ is the calculated amount of adsorbate adsorbed at time $t$, and $n$ is the number of data points.

2.5. Regeneration Study. Regeneration of CSAC was done by reactivating the saturated CSAC via microwave irradiation technique at 616 Watt for 9 minutes under the flow of $\mathrm{CO}_{2}$ gas at $150 \mathrm{~cm}^{3} / \mathrm{min}$. Once reactivated, the regenerated CSAC $\left(\mathrm{CSAC}_{\mathrm{n}}\right)$ was weighted and tested in adsorption studies. This regeneration process was repeated until 5 regeneration $\mathrm{cy}$ cles. The formula used to calculate the weight loss percentage of $\mathrm{CSAC}_{n}$ is as follows:

$$
\text { weight loss percentage }=\frac{W_{\mathrm{CSAC}}-W_{\mathrm{CSAC}_{n}}}{W_{\mathrm{CSAC}}} \times 100 \%,
$$

where $W_{\text {CSAC }}$ is the weight of saturated CSAC $(n=0)$, $W_{\text {CSAC } n}$ is the weight of regenerated CSAC at $n$ times, and $n$ is the number of the regeneration cycle. The adsorption test on adsorbates using $\mathrm{CSAC}_{n}$ was carried out at a temperature of $30^{\circ} \mathrm{C}, \mathrm{pH} 7$ of adsorbate solution, adsorbate concentration of $10 \mathrm{mg} / \mathrm{L}$, and dosage of $0.2 \mathrm{~g}$ of $\mathrm{CSAC}_{n}$ per $200 \mathrm{ml}$ of solution volume.

\section{Results and Discussion}

3.1. Characteristics of CSAC. The CSAC was found to pose high BET surface area and total pore volume which were $625.61 \mathrm{~m}^{2} / \mathrm{g}$ and $0.42 \mathrm{~cm}^{3} / \mathrm{g}$, respectively. According to Yusop et al. [15], the gasification effect of $\mathrm{CO}_{2}$ gas onto coconut shell was responsible for creating pores network. These gas molecules penetrate deep into the interior surface of the coconut shell creating more pores. The effectiveness of the microwave irradiation technique was proven when the surface area, as well as total pore volume, was found to rise due to the removal of water and volatile matter from the coconut shell. When these components evaporate and leave the sample, vacant spaces associated with the pores network were developed. The average pore diameter for CSAC was $4.55 \mathrm{~nm}$, thus confirming that all CSAC mainly contain mesoporous structure. Further verification on the type of pores was made in terms of $\mathrm{N}_{2}$ adsorption-desorption isotherms as shown in Figure 1. Based on this figure, the adsorption-desorption curve for precursor was found to follow isotherm type I which confirmed the existence of micropores on the precursor. On contrary, the $\mathrm{N}_{2}$ adsorption-desorption curve for CSAC was observed to be similar to isotherm type IV which can be identified from the hysteresis loop corresponding to the adsorption of adsorbate on mesopores [15].

The SEM image of the coconut shell and CSAC are shown in Figure 2. It can be observed that the surface of the coconut shell was rough and uneven whereas CSAC was filled with cavities distributed all over the surface. These cavities are the one referred to as the pores which play a major role as an active site to adsorb adsorbate molecules. Carbonization and activation processes succeeded in creating pores in CSAC. These pores were formed from the vacant spaces previously occupied by moisture and volatile matter components. Due to the inability of these components to withstand the heat treatment, they evaporated and left the sample [14].

The elemental spectrum and quantitative results for CSAC are shown in Figures 3 and 4, respectively. These results were obtained using Energy Dispersive X-Ray Analysis (EDX). Based on both figures, it was found that the carbon atom appears in CSAC at the highest atomic composition and weight percentage of $87.15 \%$ and $81.75 \%$, respectively. Other elements such as oxygen, aluminum, silicon, sulfur, and iron existed in CSAC in less than $13.85 \%$ and $18.25 \%$ in terms of atomic composition and weight percentage, respectively. High composition of carbon atoms in CSAC was desired as they made up the matrix in CSAC. The existence of a low percentage of inorganic elements in CSAC was an indication that coconut shell is a good precursor for activated carbon production in the first place.

The existence of polar compounds on the surface of an adsorbent very much depends on the nature of the precursor used and the method of activation employed. To verify these polar compounds, FTIR analysis was conducted, and its spectrum is given in Figure 5. The summary of bandwidth peaks together with their corresponding compounds is given in Table 2. It was revealed that the surface of CSAC was packed with a variety of polar compounds such as alcohol, nitrile, alkene, alkyne, aldehyde, and carboxylic which correspond to functional groups of $\mathrm{O}-\mathrm{H}, \mathrm{C}-\mathrm{N}, \mathrm{C}=\mathrm{C}, \mathrm{C} \equiv \mathrm{C}$, $\mathrm{C}-\mathrm{O}$, and $\mathrm{COOH}$, respectively. These functional groups attract charged adsorbates, thus increasing the adsorption capacity of CSAC. For further confirmation, zeta potential distribution is given in Figure 6. The zeta potential reading on CSAC's surface was found to be $-21 \mathrm{mv}$. This indicated the surface of CSAC was negatively charged in nature and 


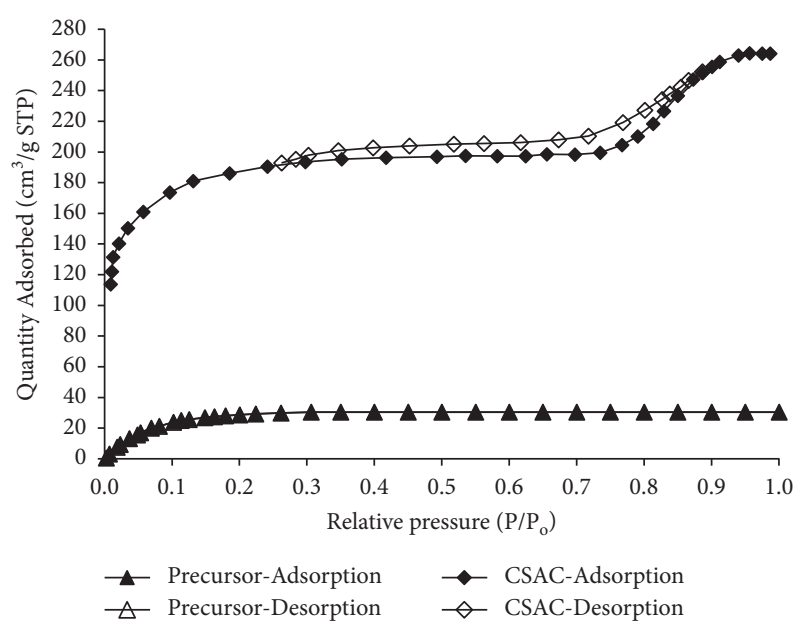

Figure 1: $\mathrm{N}_{2}$ adsorption-desorption isotherms for samples at STP.

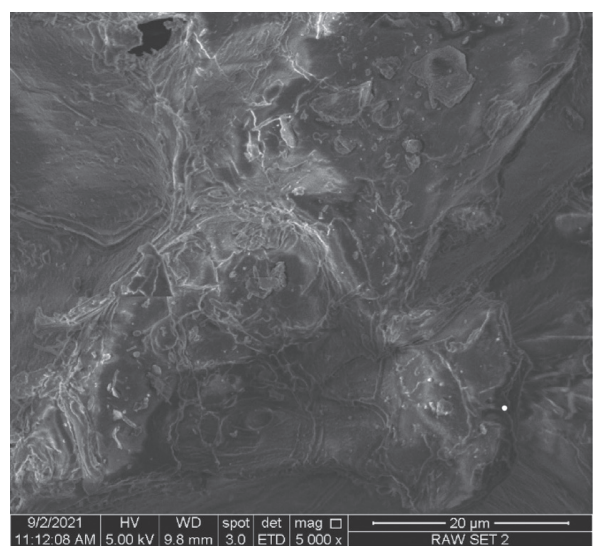

(a)

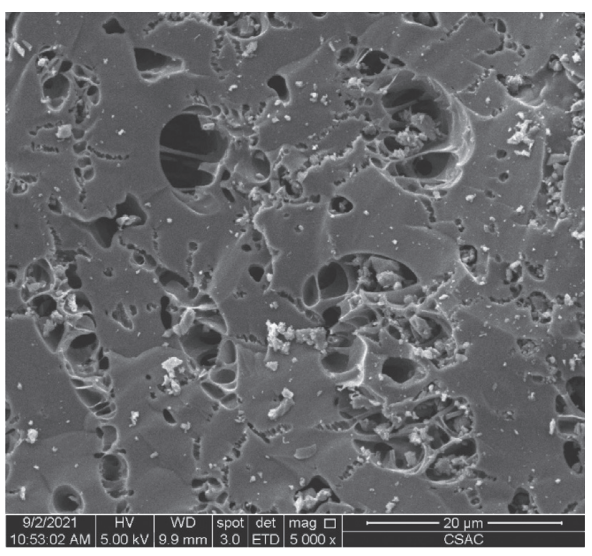

(b)

FIgURE 2: SEM image of (a) coconut shell and (b) CSAC (5000x).

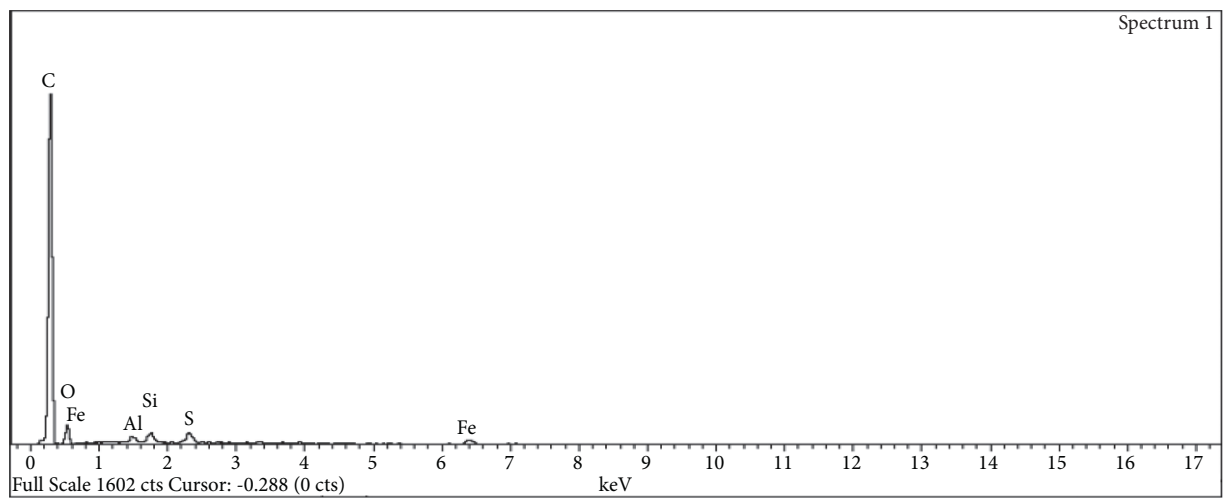

FIgURE 3: Elemental spectrum for CSAC.

CSAC has a negative surface charge (more $\mathrm{OH}^{-}$available) which contributed to the stability of the sample. A similar result was found in the research conducted by Yusop et al. [15] where the zeta potential for acacia wood-based AC was found to be negative as well.

\subsection{Optimization Studies}

3.2.1. Regression Model Development. The complete matrix of experimental design in preparing CSAC is shown in Table 3 . The software had suggested a quadratic model suit 


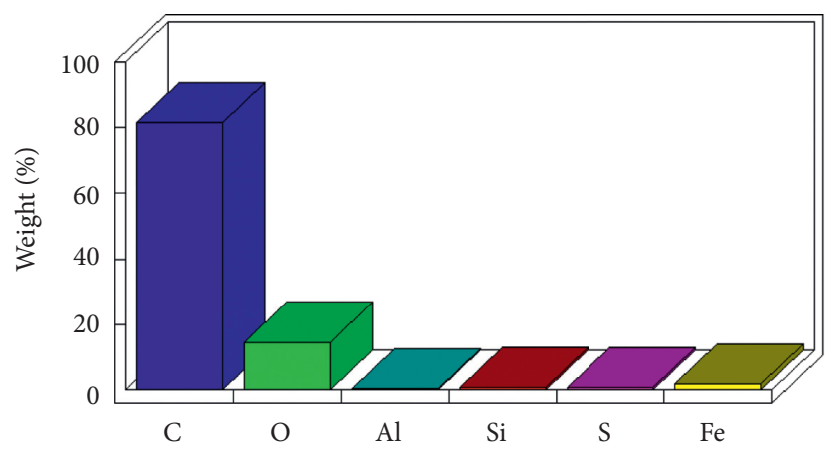

FIGURE 4: Quantitative results for CSAC.

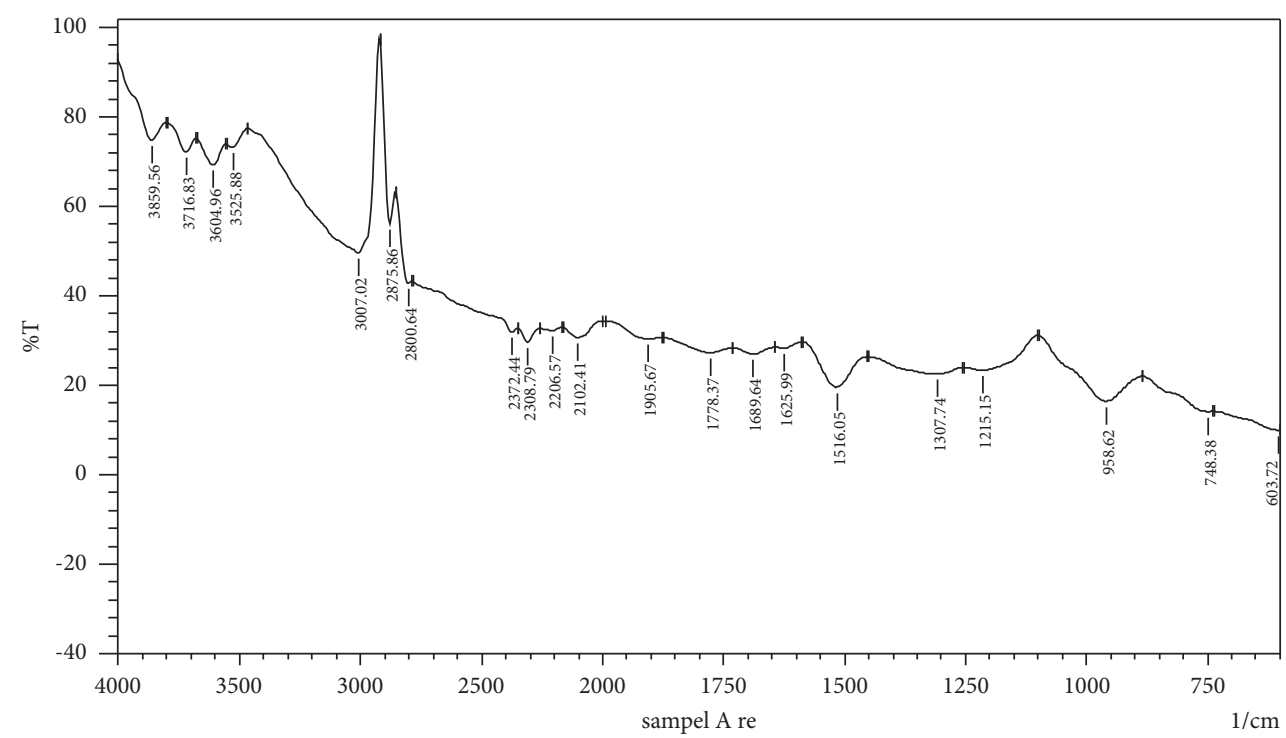

FIGURE 5: FTIR spectra.

TABLE 2: Summary of FTIR spectra.

\begin{tabular}{lcc}
\hline Peak & Intensity & Compounds \\
\hline 748 & Weak & Alcohol, O-H \\
1215 & Weak & Nitrile, C-N \\
1625 & Weak & Alkene, C=C \\
1689 & Weak & Alkene, C=C \\
1778 & Weak & Alkene, C=O \\
2102 & Weak & Alkyne, C=C \\
2206 & Weak & Nitrile, C-N \\
2308 & Weak & Nitrile, C-N \\
2800 & Medium & Aldehyde, C=O \\
2875 & Medium & Carboxylic, COOH \\
3007 & Medium & Carboxylic, COOH \\
3525 & Strong & Carboxylic, COOH \\
3604 & Strong & Alcohol, O-H \\
3716 & Strong & Alcohol, O-H \\
\hline
\end{tabular}

for both responses of DDT removal and CSAC's yield. The experimental values for DDT removal were found to be between 60.54 and $92.53 \%$ whereas the same values for

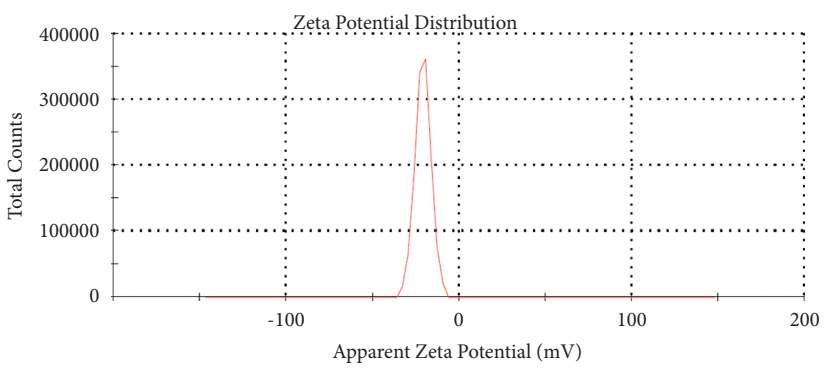

FIgURE 6: Zeta potential for CSAC.

CSAC's yield were observed to be between 16.17 and $43.24 \%$. In terms of coded factors, the empirical models that correlate variables to responses are provided as follows.

DDT removal, $Y_{1}$ :

$$
Y_{1}=80.86+12.80 X_{1}+4.00 X_{2}-4.39 X_{1}^{2}-1.34 X_{2}^{2}+1.58 X_{1} X_{2} \text {. }
$$

CSAC's yield, $Y_{2}$ : 
TABLE 3: Complete experimental design matrix for CSAC's preparation.

\begin{tabular}{lcccc}
\hline \multirow{2}{*}{ Run } & \multicolumn{2}{c}{ CSAC's preparation variables } & \multicolumn{2}{c}{ Responses } \\
& Radiation power, $X_{1}$ (Watt) & Radiation time, $X_{2}(\mathrm{~min})$ & DDT removal, $Y_{1}(\%)$ & CSAC's yield, $Y_{2}(\%)$ \\
\hline 1 & $490.00(0)$ & $2.00(-1)$ & 74.11 & 41.88 \\
2 & $490.00(0)$ & $4.00(0)$ & 82.45 & 39.83 \\
3 & $490.00(0)$ & $6.00(+1)$ & 85.66 & 38.13 \\
4 & $490.00(0)$ & $4.00(0)$ & 92.53 & 33.34 \\
5 & $616.00(+1)$ & $6.00(+1)$ & 89.45 & 18.25 \\
6 & $616.00(+1)$ & $4.00(0)$ & 80.11 & 36.17 \\
7 & $490.00(0)$ & $4.00(0)$ & 81.36 & 40.54 \\
8 & $490.00(0)$ & $4.00(0)$ & 63.59 & 40.12 \\
9 & $364.00(-1)$ & $2.00(-1)$ & 78.96 & 33.24 \\
10 & $364.00(-1)$ & $6.00(+1)$ & 83.15 & 39.38 \\
11 & $490.00(0)$ & $4.00(0)$ & 64.22 & 35.29 \\
12 & $616.00(+1)$ & $2.00(-1)$ & 40 \\
13 & $364.00(-1)$ & $4.00(0)$ & & 28.14 \\
\hline
\end{tabular}

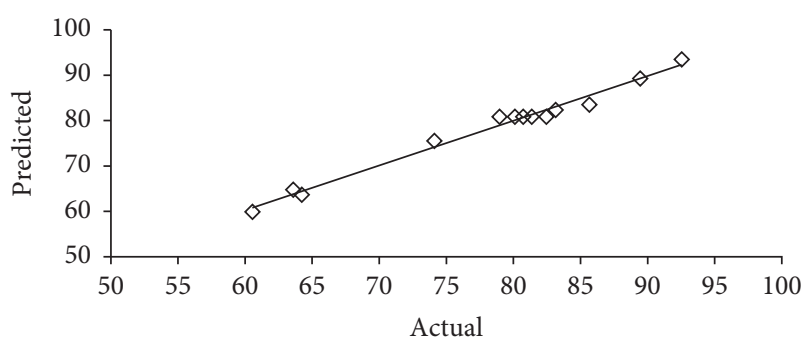

(a)

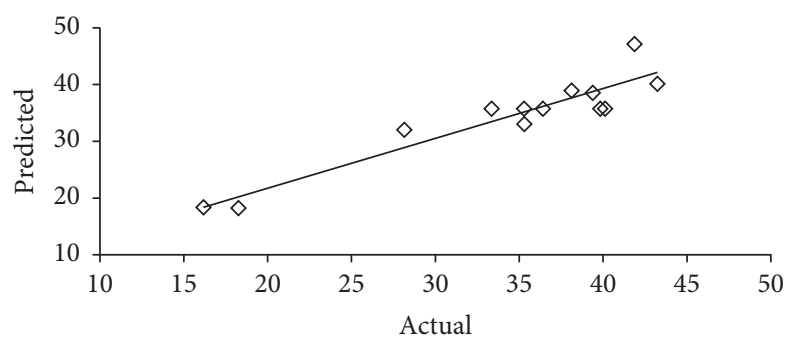

(b)

Figure 7: Plot of predicted versus actual (a) DDT removal and (b) CSAC's yield.

$Y_{2}=35.77-6.84 X_{1}-4.11 X_{2}-10.55 X_{1}^{2}+7.29 X_{2}^{2}-3.33 X_{1} X_{2}$

Figures 7(a) and 7(b) present the predicted versus actual plots for DDT removal and CSAC's yield, respectively. These plots were validated by using three parameters namely correlation coefficient, $R^{2}$, standard deviation (SD), and last but not least, adequate precision (AP). Equations (11) and (12) produce satisfactory high $R^{2}$ values of 0.9855 and 0.8786 , respectively, which reflected $98.55 \%$ and $87.86 \%$ of the total variation in the responses of DDT removal and CSAC's yield, respectively, coming from the variables studied. Moreover, low SD values were obtained for equations (11) and (12) of 1.57 and 3.89, respectively, which confirmed that only a small deviation of predicted data from actual data has occurred. In terms of AP, equations (11) and (12) generated 31.53 and 10.93, respectively. AP measured signal to noise ratio. Since these values were greater than 4 , then these models were adequate to navigate the design space.

3.2.2. Analysis of Variance (ANOVA). Analysis of variance (ANOVA) is useful to help us understand the experimental data better. If the value produced by ANOVA for Prob $>\mathrm{F}$ and $F$ value are less than 0.05 and high, respectively, it indicates that the term model is significant to the response and the result is not random $[36,37]$. The results of ANOVA for DDT removal and CSAC's yield are shown in Table 4, respectively. The models of these responses were both significant due to Prob $>$ F value for DDT removal and CSAC's yield were $<0.0001$ and 0.0042 , respectively. Lack of fit was observed to be insignificant for both responses studied, thus concluding that variables used had a notable effect on the responses and the models fitted the experimental data nicely [20].

Based on Table 4, the terms of $X_{1}$ (radiation power), $X_{2}$ (radiation time), and $X_{1}^{2}$ (quadratic effect of radiation power) were found to be significant for DDT removal response whereas other terms not mentioned were not significant. F values obtained for radiation power and radiation time were 399.51 and 38.97, respectively, thus signifying that radiation power affects DDT removal way, superior compared to radiation time. Based on Table 4, significant terms for CSAC's yield response were found to be $X_{1}$ (radiation power), $X_{2}$ (radiation time), $X_{1}^{2}$ (quadratic effect of radiation power), and $X_{2}^{2}$ (quadratic effect of radiation time), while other terms not mentioned were insignificant. F-value was found to be 18.53 and 6.69 for radiation power and radiation time, respectively. This implied that radiation power caused a greater impact on CSAC's yield response compared to radiation time.

3.2.3. Three-Dimensional (3D) Response Surface of CSAC. The pattern of variables in affecting the responses can be recognized better by observing the three-dimensional (3D) response surface. The $3 \mathrm{D}$ response surface plot for DDT 
TABLE 4: ANOVA result for DDT removal and CSAC's yield.

\begin{tabular}{|c|c|c|c|c|c|c|c|}
\hline & Source & Sum of squares & DF & Mean square & $F$ value & Prob $>F$ & \\
\hline \multirow{10}{*}{ DDT removal } & Model & 1170.97 & 5 & 234.19 & 95.23 & $<0.0001$ & \multirow[t]{7}{*}{ Significant } \\
\hline & $x_{1}$ & 982.53 & 1 & 982.53 & 399.51 & $<0.0001$ & \\
\hline & $x_{2}$ & 95.84 & 1 & 95.84 & 38.97 & 0.0004 & \\
\hline & $x_{1}^{2}$ & 53.24 & 1 & 53.24 & 21.65 & 0.0023 & \\
\hline & $x_{2}^{2}$ & 4.96 & 1 & 4.96 & 2.02 & 0.1984 & \\
\hline & $x_{1} x_{2}$ & 10.02 & 1 & 10.02 & \multirow[t]{2}{*}{4.07} & \multirow[t]{2}{*}{0.0834} & \\
\hline & Residual & 17.22 & 7 & 2.46 & & & \\
\hline & Lack of fit & 10.34 & 3 & 3.45 & 2.01 & 0.2554 & \multirow[t]{3}{*}{ Not significant } \\
\hline & Pure error & 6.87 & 4 & 1.72 & & & \\
\hline & Cor total & 1188.18 & 12 & 234.19 & 95.23 & $<0.0001$ & \\
\hline \multirow{10}{*}{ CSAC's yield } & Model & 767.82 & 5 & 153.56 & 10.14 & 0.0042 & \multirow[t]{7}{*}{ Significant } \\
\hline & $x_{1}$ & 280.66 & 1 & 280.66 & 18.53 & 0.0035 & \\
\hline & $x_{2}$ & 101.42 & 1 & 101.42 & 6.69 & 0.0361 & \\
\hline & $x_{1}^{2}$ & 307.69 & 1 & 307.69 & 20.31 & 0.0028 & \\
\hline & $x_{2}^{2}$ & 146.87 & 1 & 146.87 & 9.69 & 0.0170 & \\
\hline & $x_{1} x_{2}$ & 43.48 & 1 & 43.48 & 2.87 & 0.1341 & \\
\hline & Residual & 106.05 & 7 & 15.15 & & & \\
\hline & Lack of fit & 71.65 & 3 & 23.88 & 2.78 & 0.1744 & \multirow[t]{3}{*}{ Not significant } \\
\hline & Pure error & 34.40 & 4 & 8.60 & & & \\
\hline & Cor total & 767.82 & 5 & 153.56 & 10.14 & 0.0042 & \\
\hline
\end{tabular}

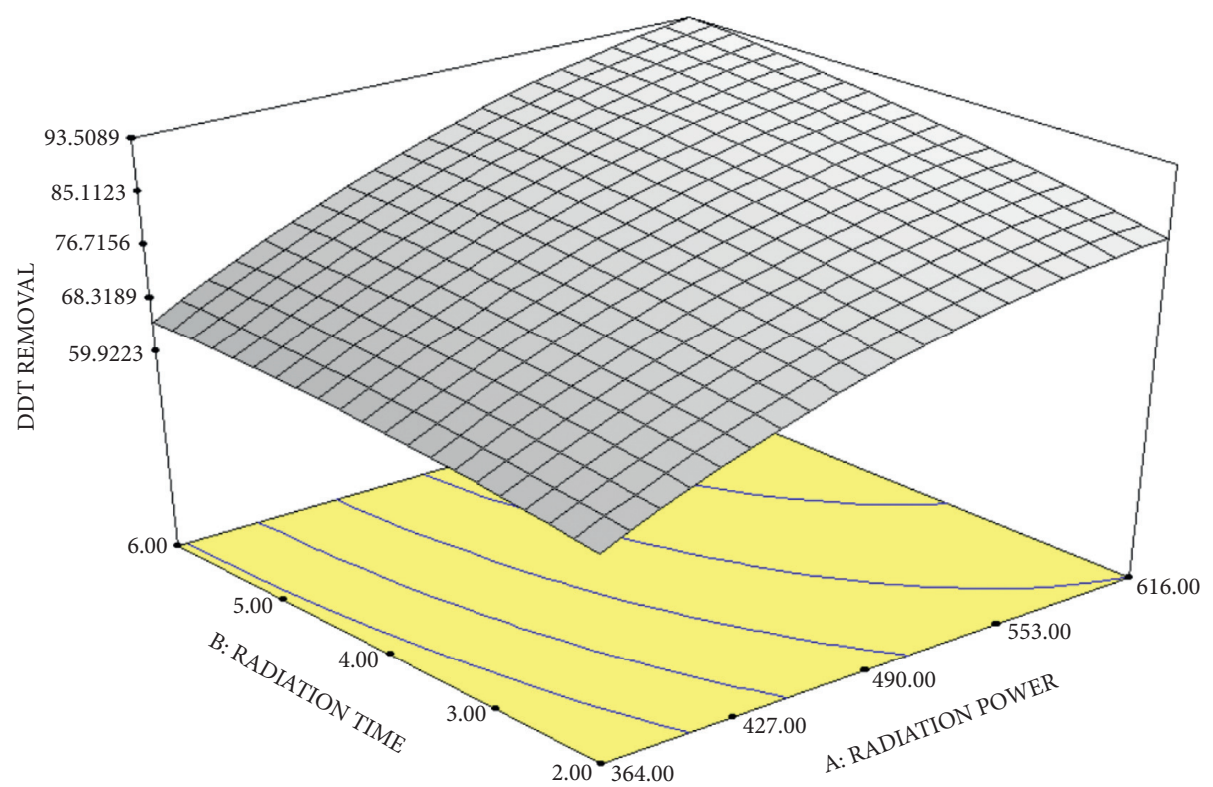

(a)

FIGURE 8: Continued. 


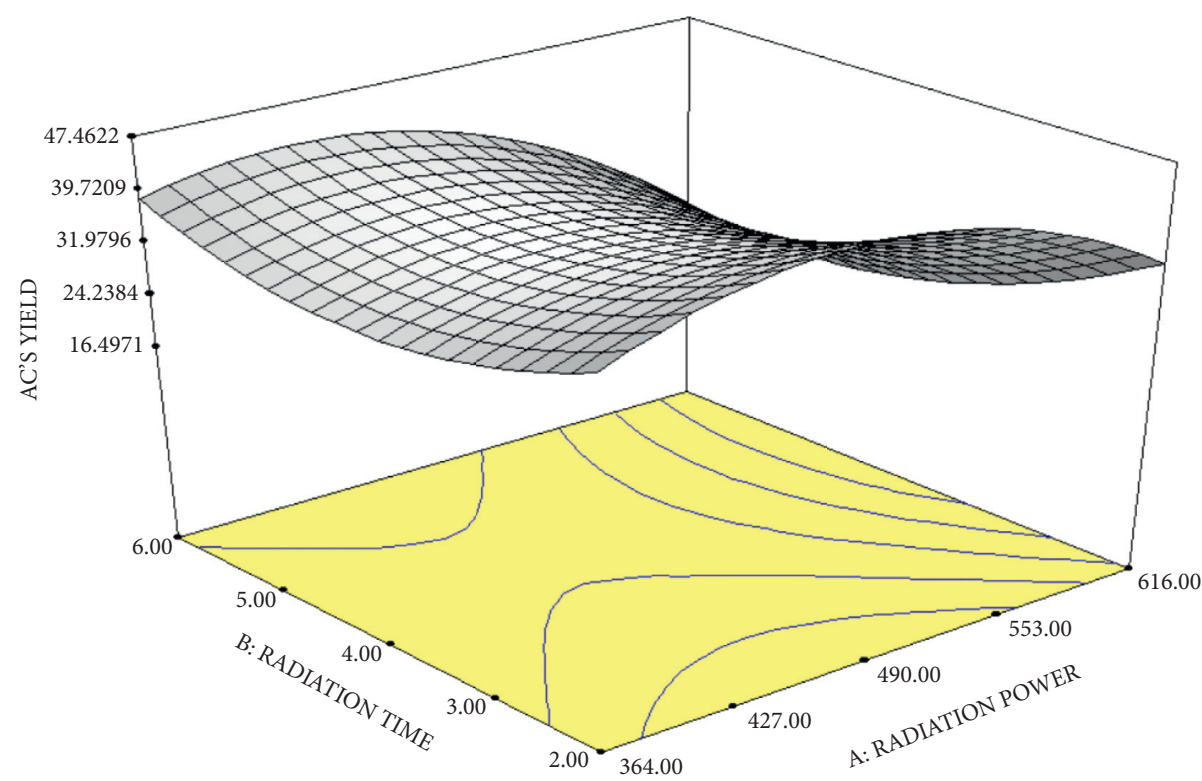

(b)

Figure 8: 3D response surface plots for (a) DDT removal and (b) CSAC's yield.

removal and CSAC's yield are shown in Figures 8(a) and 8(b), respectively.

Based on Figure 8(a), DDT removal was at the lowest point when both radiation power and radiation time were at the lowest values within the studied range. At low radiation power $(<490 \mathrm{~W})$, increasing the radiation time had caused no significant change in DDT removal. At low radiation power, not enough energy was created to change the volatile matter from solid to gas form and thus was unable to eliminate them to create more pores. Therefore, adding more radiation time would not be helpful to create pores on CSAC as well. As the result, no significant change in the adsorption capacity of DDT was observed. However, at radiation power above $490 \mathrm{~W}$, an increase in radiation time had caused a great increase in DDT removal. At high radiation power, an aggressive cracking reaction took place that enhanced the removal of volatile matter from the sample, creating more pores. The gasification effect of $\mathrm{CO}_{2}$ became more combative at higher temperatures and bombarded the external and internal surface of the sample, developing more pores which directly contributed to the higher adsorption capacity of DDT. The highest DDT removal was obtained when both radiation power and radiation time were at the maximum values within the studied range.

Based on Figure 8(b), both radiation power and radiation time were observed to pose a negative impact on CSAC's yield. When radiation power was at the lowest value within the studied range, CSAC's yield was found to be at the maximum value. As radiation power increased, CSAC's yield reduced significantly. Similarly, increasing radiation time caused CSAC's yield to decrease as well. At high radiation power, an aggressive volatilization process occurred which led to a reduction in CSAC's weight. According to Yusop et al. [15], an increase in radiation time permitted the volatilization process to be elongated, therefore decreasing
CSAC's yield even more. At the highest values of radiation power and radiation time within the studied range, the lowest CSAC yield was found to exist. A similar trend was found in the study of removing cationic dye by acacia woodbased AC where the maximum level of radiation power and radiation time produced a minimum level of AC's yield [15].

3.2.4. Optimization of CSAC's Preparation Variables. Radiation power and radiation time were known to pose a positive effect on adsorption capacity and a negative effect on AC's yield. Due to this contradicted effect, RSM based on CCD was exploited in this research to search for optimum values of DDT removal and CSAC's yield. In doing so, variables were set to be in the range while responses were set to be maximum. Table 5 shows the validation model for CSAC's preparation. It was found that optimum radiation power and radiation time were $502 \mathrm{~W}$ and $6 \mathrm{~min}$, which resulted in $84.83 \%$ of DDT removal and $37.91 \%$ of CSAC's yield. The excellence of the models developed in this study to predict the responses was proven by the small error percentage obtained of $2.79 \%$ and $2.11 \%$ for DDT removal and CSAC's yield, respectively.

3.3. Equilibrium Studies. The plot of DDT uptakes and DDT percentage removal by CSAC versus time at different initial concentrations are given in Figures 9 and 10, respectively.

It was observed that DDT uptakes and percentage removal increased with time until a constant value was reached. This constant value indicated a saturation point where CSAC had reached its limit in adsorbing DDT. At the beginning of the adsorption process, CSAC had plenty of active sites ready to be occupied by the DDT's molecules. After sometimes, the number of active sites available on CSAC decreased and repulsion between DDT's molecules in 
TABLE 5: Model validation for CSAC's preparation.

\begin{tabular}{lccccccc}
\hline \multicolumn{2}{c}{ Variables } & \multicolumn{3}{c}{ Responses } \\
Radiation power, $X_{1}$ (Watt) & Radiation time, $X_{2}(\mathrm{~min})$ & \multicolumn{2}{c}{ DDT removal, $Y_{1}(\%)$} & \multicolumn{3}{c}{ AC's yield, $Y_{2}(\%)$} \\
& & Predicted & Actual & Error & Predicted & Actual & Error \\
\hline 502 & 6.00 & 84.83 & 82.46 & 2.79 & 37.91 & 37.11 & 2.11 \\
\hline
\end{tabular}

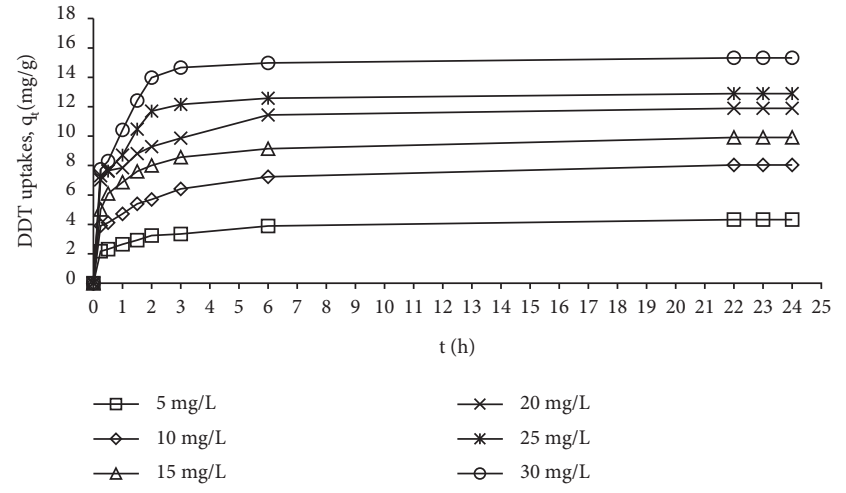

FIgURE 9: Adsorption uptakes of DDT by CSAC versus time at various initial concentrations (solution temperature of $30^{\circ} \mathrm{C}$, adsorbent dose of $0.2 \mathrm{~g}$ solution volume of $200 \mathrm{~mL}$, and solution $\mathrm{pH}$ of 7).

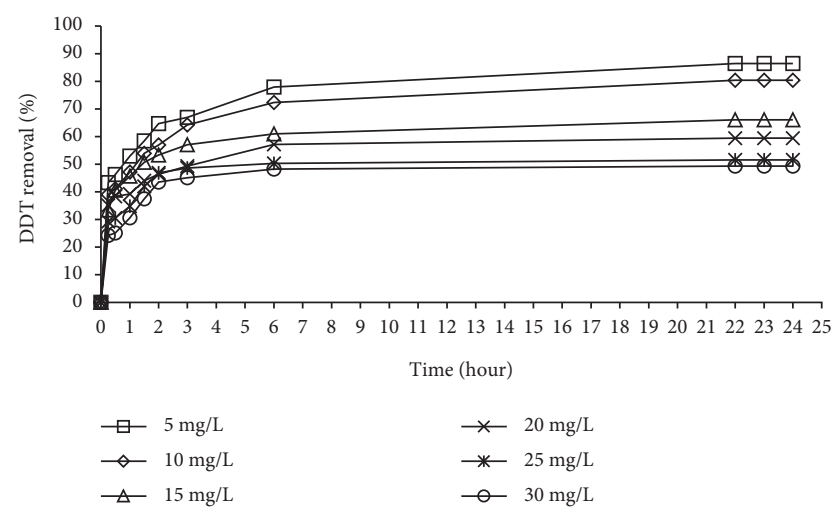

Figure 10: Percentage removal of DDT by CSAC versus time at various initial concentrations (solution temperature of $30^{\circ} \mathrm{C}$, adsorbent dose of $0.2 \mathrm{~g}$ solution volume of $200 \mathrm{~mL}$, and solution $\mathrm{pH}$ of 7).

the solid phase and bulk phase started to occur and get stronger [38]. In the end, an equilibrium state was achieved where the rate of adsorption and rate of desorption were equal [39].

As the initial concentration increased from 5 to $30 \mathrm{mg} / \mathrm{L}$, adsorption uptakes of DDT increased from 4.32 to $15.32 \mathrm{mg} /$ g. This phenomenon can be explained by the greater mass transfer driving force developed at a higher initial concentration to overcome mass transfer resistance between adsorbates in the bulk phase and adsorbates in the solid phase, thus resulted in higher adsorbate uptakes [40]. On contrary, as the initial concentration of DDT increased, the percentage removal of DDT was noticed to decrease from 86.44 to $49.33 \%$. Low percentage removal at higher initial concentrations occurred because the ratio of an initial number of adsorbates' molecules to the available surface area was high, making the active sites to be saturated easily [41].

3.4. Isotherm Study. Three adsorption isotherms of Langmuir, Freundlich, and Temkin were used in this study. The parameters and constants generated from these isotherms can provide information comprised of adsorbates molecules distribution on the surface of adsorbents at equilibrium [42] and adsorption capacity of adsorbents [43]. The plots of linearized equations for Langmuir, Freundlich, and Temkin for DDT uptakes by CSAC are given in Figure 11. Parameters of isotherms used in this study are summarized in Table 6.

The correlation coefficient $R^{2}$ was evaluated to determine which isotherm model suited the DDT-CSAC adsorption system the best. It was found that this adsorption system was best described by Langmuir isotherm due to the high $R^{2}$ obtained of 0.9995. Langmuir isotherm signified that adsorption of DDT onto CSAC formed a monolayer coverage with maximum Langmuir monolayer adsorption capacity, and $Q_{m}$ was found to be $14.51 \mathrm{mg} / \mathrm{g}$. The adsorption capacity of DDT obtained in this study was compared with other studies and is summarized in Table 7. One important parameter that can be evaluated from the Freundlich isotherm is the heterogeneity factor, $n_{\mathrm{F}}$. Since the $n_{\mathrm{F}}$ value of this adsorption system was between 1 and 10, it signified that this adsorption process was favorable.

3.5. Kinetic Study. Two kinetics models namely pseudo-firstorder (PFO) and pseudo-second-order (PSO) were employed in this study to give better insight into the kinetic behaviour of the adsorption systems studied. The important findings in kinetics studies included the determination of the kinetic rate constant and the type of adsorption associated with the rate-limiting step, which is either physisorption or chemisorption. The linearized plots of PFO and PSO for DDT uptakes by CSAC are given in Figures 12(a) and 12(b), respectively. Table 8 shows the kinetic parameters for the DDT-CSAC adsorption system.

PSO was found to fit the kinetic data the best for the DDT-CSAC adsorption system due to high $R^{2}$ and relatively low error percentages of $>0.95$ and $<11.90 \%$, respectively. Therefore, the rate-limiting step for this adsorption system may be contributed by chemisorption. A low error percentage was desired because it signified that the kinetic model succeeded in predicting the adsorption capacity of adsorbates at equilibrium. The value of $k_{2}$ showed a trend where this value decreased when the initial concentration of DDT increased. At higher concentrations, the ratio of 


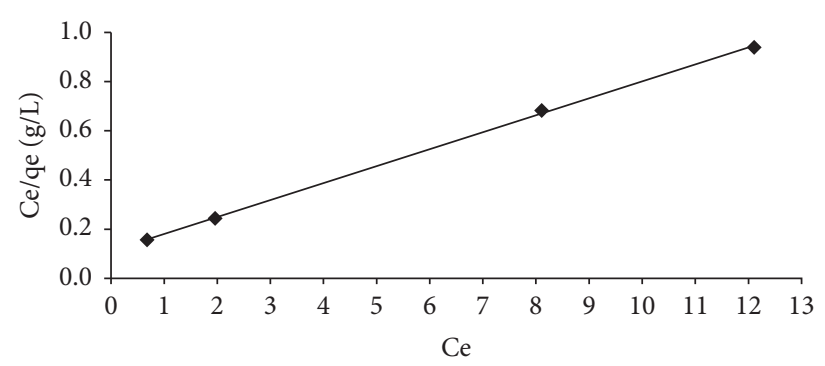

- 30C

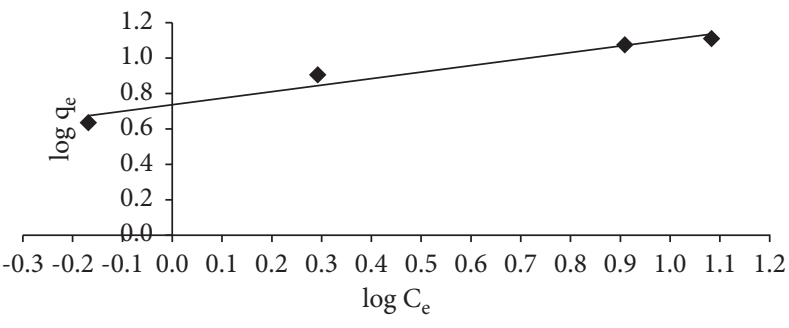

- $30 \mathrm{C}$

(a)

(b)

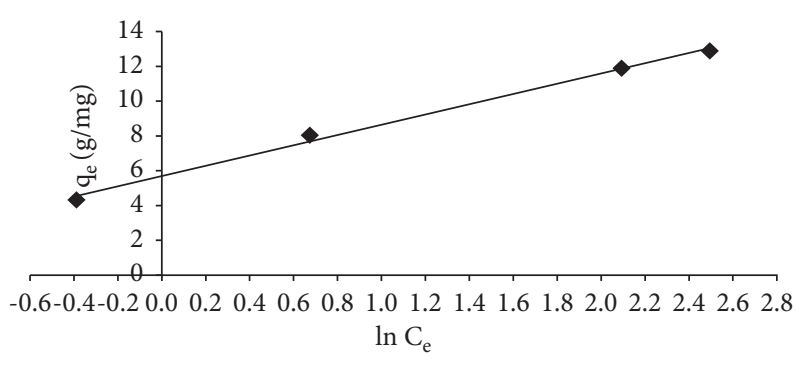

- 30C

(c)

Figure 11: Linearized plots of (a) Langmuir, (b) Freundlich, and (c) Temkin models for DDT adsorption onto CSAC (solution temperature of $30^{\circ} \mathrm{C}$, adsorbent dose of $0.2 \mathrm{~g}$ solution volume of $200 \mathrm{~mL}$, and solution $\mathrm{pH}$ of 7 ).

TABLE 6: Isotherm parameters for adsorption of adsorbates onto CSAC at $30^{\circ} \mathrm{C}$.

\begin{tabular}{lr}
\hline Parameters & Isotherms \\
\hline & Langmuir \\
$Q_{m}(\mathrm{mg} / \mathrm{g})$ & 14.51 \\
$K_{L}(\mathrm{~L} / \mathrm{mg})$ & 0.62 \\
$R^{2}$ & 0.9995 \\
\hline & Freundlich \\
$n_{F}$ & 2.71 \\
$K_{F}(\mathrm{mg} / \mathrm{g})(\mathrm{L} / \mathrm{mg}) 1 / n$ & 5.45 \\
$R^{2}$ & 0.9583 \\
$1 / n_{F}$ & 0.37 \\
\hline & Temkin \\
$B_{T}(\mathrm{~L} / \mathrm{mg})$ & 2.95 \\
$A_{T}(\mathrm{~L} / \mathrm{mg})$ & 6.91 \\
$R^{2}$ & 0.9555 \\
\hline
\end{tabular}

TABLE 7: Comparison of DDT adsorption capacity by different types of adsorbents.

\begin{tabular}{lccc}
\hline Precursor & Adsorption capacity $(\mathrm{mg} / \mathrm{g})$ & Activation type & References \\
\hline Coconut shell & 14.51 & Physical activation & This study \\
Commercial AC (PAC F400) & 163.90 & Physical activation & No activation \\
Wood sawdust & 69.44 & No activation & \\
Cork waste & 19.08 & Solvothermal reaction & [44] \\
Silica & 7.50 & No activation & {$[45]$} \\
Carbon nanotube & 0.25 & No activation (biosorbent) & {$[46]$} \\
Eucalyptus bark & 0.013 & No activation (biosorbent) & {$[47]$} \\
Rice roots & $7.21 \times 10^{-6}$ & & [48] \\
\hline
\end{tabular}




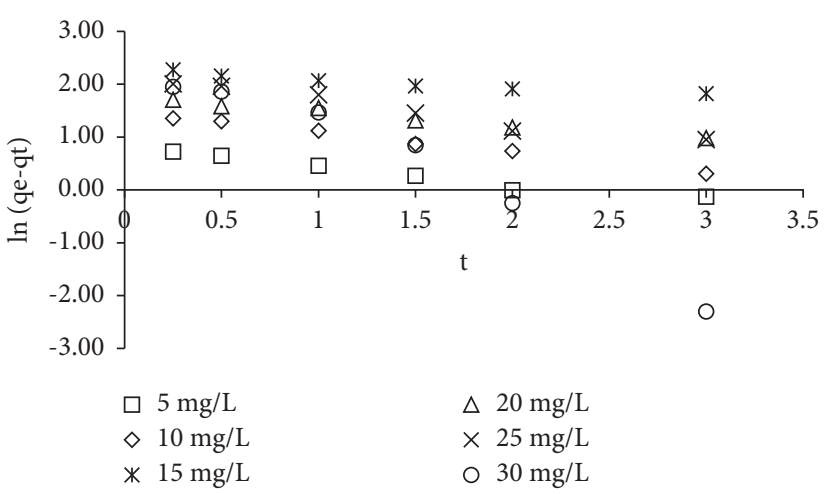

(a)

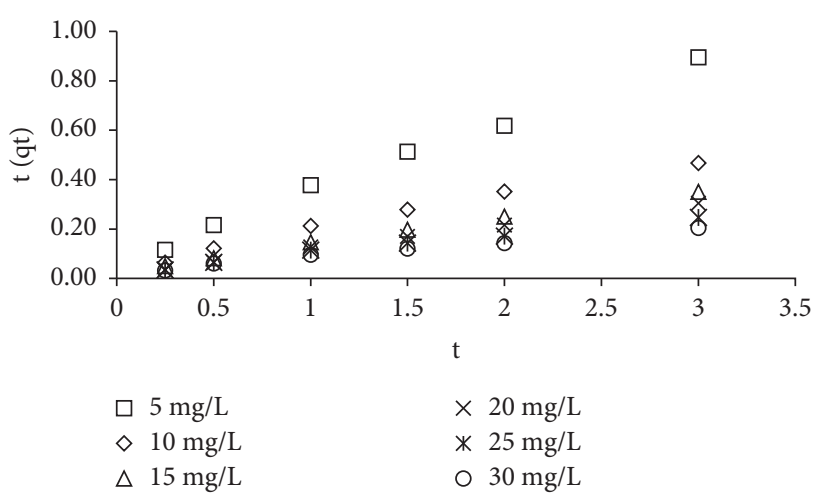

(b)

Figure 12: Linearized plots of (a) PFO and (b) PSO models for the DDT-CSAC system (solution temperature of $30^{\circ} \mathrm{C}$, adsorbent dose of $0.2 \mathrm{~g}$, solution volume of $200 \mathrm{~mL}$, and solution $\mathrm{pH}$ of 7 ).

TABLE 8: Kinetic parameters for the DDT-CSAC adsorption system at $30^{\circ} \mathrm{C}$.

\begin{tabular}{|c|c|c|c|c|c|c|c|c|c|}
\hline \multirow{2}{*}{$\begin{array}{l}\text { Adsorbate initial concentration } \\
(\mathrm{mg} / \mathrm{L})\end{array}$} & \multirow{2}{*}{$q_{e}, \exp (\mathrm{mg} / \mathrm{g})$} & \multicolumn{4}{|c|}{ Pseudo-first-order } & \multicolumn{4}{|c|}{ Pseudo-second-order } \\
\hline & & $q_{e}, \mathrm{cal}(\mathrm{mg} / \mathrm{g})$ & $k_{1}\left(\mathrm{~s}^{-1}\right)$ & $R^{2}$ & $\Delta q_{t}(\%)$ & $q_{e}, \mathrm{cal}(\mathrm{mg} / \mathrm{g})$ & $k_{2}(\mathrm{~L} / \mathrm{mol} . \mathrm{s})$ & $R^{2}$ & $\Delta q_{t}(\%)$ \\
\hline 5 & 4.32 & 2.19 & 0.33 & 0.96 & 49.28 & 3.83 & 0.91 & 0.99 & 11.38 \\
\hline 10 & 8.04 & 4.39 & 0.39 & 0.99 & 45.44 & 7.08 & 0.44 & 0.98 & 11.90 \\
\hline 15 & 9.91 & 9.50 & 0.16 & 0.93 & 4.17 & 9.19 & 0.40 & 0.99 & 7.25 \\
\hline 20 & 11.89 & 5.77 & 0.27 & 0.98 & 51.44 & 10.63 & 0.40 & 0.99 & 10.62 \\
\hline 25 & 12.89 & 8.46 & 0.43 & 0.95 & 34.34 & 13.50 & 0.20 & 0.95 & 4.70 \\
\hline 30 & 15.32 & 15.61 & 1.56 & 0.95 & 1.88 & 16.72 & 0.13 & 0.99 & 9.15 \\
\hline
\end{tabular}

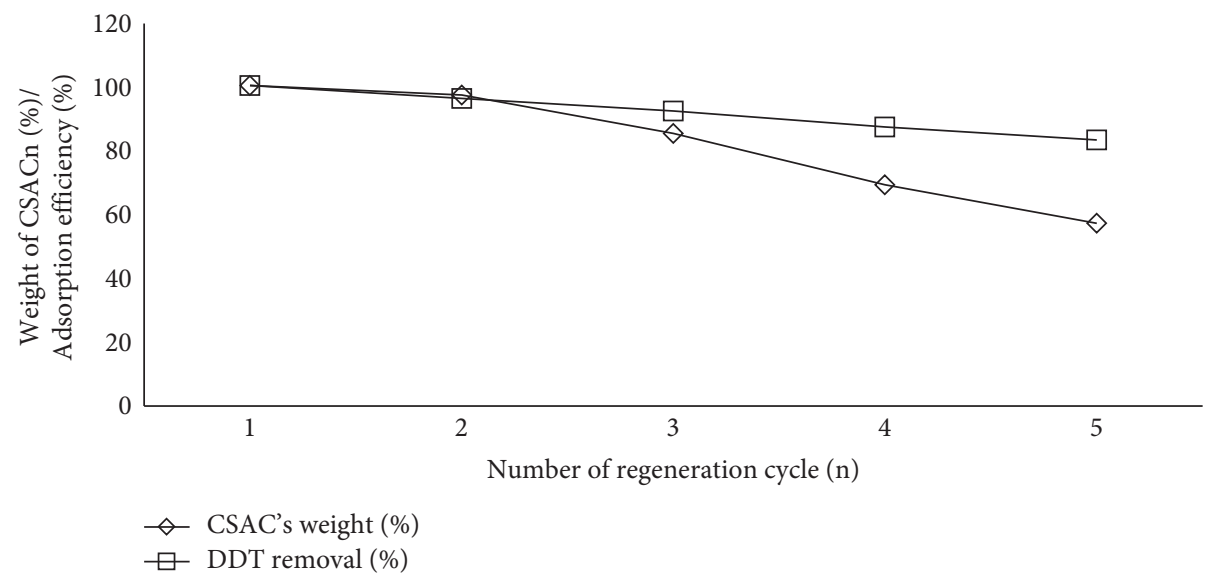

FIGURE 13: Regeneration plots of (a) DDT-CSAC ${ }_{\mathrm{n}}$ adsorption system (solution temperature of $30^{\circ} \mathrm{C}$, adsorbate concentration of $10 \mathrm{mg} / \mathrm{L}$, adsorbent dose of $0.2 \mathrm{~g}$, solution volume of $200 \mathrm{~mL}$, and solution $\mathrm{pH}$ of 7).

adsorbate to the available surface area was high, resulting in a slower adsorption process and lower rate constant [49].

3.6. Regeneration Study. Regeneration study is vital in promoting sustainability and reducing the cost of producing new CSAC. However, any AC can only bear to be regenerated several times only due to the significant loss in weight percentage and adsorption performance. Figure 13 shows the regeneration plot for DDT-CSAC $n$ studied.
Based on the regeneration plot, it was revealed that both weights of $\mathrm{CSAC}_{n}$ and the adsorption efficiency had dropped on every regeneration cycle. To be exact, the weight loss percentage of $\mathrm{CSAC}_{n}$ had occurred from $100 \%$ to $57 \%$ after 5 regeneration cycles. Similarly, the adsorption efficiency of $\mathrm{CSAC}_{n}$ in removing DDT had decreased from $100 \%$ to $83 \%$ after 5 regeneration cycles. The reduction in weight and adsorption efficiency can be explained by the ruptured carbon matrix that made up CSAC's structure after it was reactivated using the microwave irradiation technique. This 
leads to the damaged of pores, thus reducing the number of active sites for the adsorption process to take place. For the economic reason, it is best to stop the regeneration cycle after 4 times only because, at the $5^{\text {th }}$ regeneration cycle, the weight of $\mathrm{CSAC}_{\mathrm{n}}$ had dropped almost half than the original weight and became less efficient.

\section{Conclusions}

Coconut-shell-based AC (CSAC) was successfully synthesized with the aid of microwave irradiation technique together with $\mathrm{CO}_{2}$ gasification. CSAC showed moderately high BET surface and pore volume of $625.61 \mathrm{~m}^{2} / \mathrm{g}$ and $0.42 \mathrm{~cm}^{3} / \mathrm{g}$, respectively. The average pore diameter for CSAC was found to be $4.55 \mathrm{~nm}$ which lies in the mesopores region. $\mathrm{N}_{2}$ adsorption-desorption curves on CSAC followed isotherm type IV which further confirmed the domination of mesopores type of pores on CSAC. The elemental spectrum showed that $87.15 \%$ of CSAC has consisted of the carbon atom, which made up the matrix. A high percentage of carbon proved that coconut shell is the best choice of precursor in the first place. FTIR spectrum confirmed the existence of many polar groups on CSAC's surface such as alcohol $(\mathrm{O}-\mathrm{H})$, nitrile $(\mathrm{C}-\mathrm{N})$, alkene $(\mathrm{C}=\mathrm{C})$, alkyne $(\mathrm{C} \equiv \mathrm{C})$, aldehyde $(\mathrm{C}=\mathrm{O})$, and carboxylic acid $(\mathrm{COOH})$. In nature, CSAC's surface was negatively charged due to the zeta potential value of $-21 \mathrm{mV}$. Optimization study revealed that the optimum preparation conditions of CSAC were $502 \mathrm{~W}$ and $6 \mathrm{~min}$ for radiation power and radiation time, respectively, which resulted in $84.83 \%$ of DDT removal and $37.91 \%$ of CSAC's yield. A small error percentage of $2.79 \%$ and $2.11 \%$ for responses of radiation power and radiation time, respectively, signified the success of the models developed to predict actual data. An equilibrium study divulged that the adsorption uptakes of DDT increased from 4.32 to $15.32 \mathrm{mg} / \mathrm{g}$ as the initial concentration increased from 5 to $30 \mathrm{mg} / \mathrm{L}$. Conversely, DDT percentage removal dropped from 86.44 to $49.33 \%$ as the initial concentration increased from 5 to $30 \mathrm{mg} / \mathrm{L}$. DDT-CSAC adsorption system followed Langmuir isotherm with monolayer adsorption capacity, $Q_{m}$ of $14.51 \mathrm{mg} / \mathrm{g}$. This adsorption system was favorable due to the fact that the $n_{F}$ parameter from Freundlich isotherm was found to be 2.71. In terms of kinetic, the adsorption of DDT onto CSAC was best described by PSO which signified the role of chemisorption in the adsorption process. As initial concentration increased from 5 to $30 \mathrm{mg} / \mathrm{L}$, the rate constant $k_{2}$ decreased from 0.91 to $0.13 \mathrm{~L} / \mathrm{mol}$.s due to a slower adsorption process at higher initial concentration. Regeneration study divulged that both adsorption performance and CSAC's weight decreased from 100 to $83 \%$ and 100 to $57 \%$, respectively, after 5 regeneration cycles.

\section{Data Availability}

Data are available upon request to the corresponding author via e-mail.

\section{Conflicts of Interest}

The authors declare that they have no conflicts of interest.

\section{Acknowledgments}

This research was supported by the Malaysian Ministry of Higher Education under the Fundamental Research Grant Scheme (project code: FRGS/1/2021/TK0/USM/01/3).

\section{References}

[1] X. Wang, Y. Tan, M. Gao, W. Liu, and Y. Yu, "Bioaccessibility dependence of dietary exposure to dichlorodiphenyltrichloroethane and its metabolites and hexachlorocyclohexane isomers and their induced health risk: a case study in Beijing City, China," Environmental Pollution, vol. 281, Article ID 117065, 2021.

[2] P. R. S. Kodavanti, J. E. Royland, and K. R. S. Sambasiva Rao, "Toxicology of persistent organic pollutants," Reference Module in Biomedical Sciences, Elsevier, Amsterdam, Netherlands, 2014.

[3] Y. Chen, D. Zhi, Y. Zhou et al., "Electrokinetic techniques, their enhancement techniques and composite techniques with other processes for persistent organic pollutants remediation in soil: a review," Journal of Industrial and Engineering Chemistry, vol. 97, pp. 163-172, 2021.

[4] W. Guo, B. Pan, S. Sakkiah et al., "Persistent organic pollutants in food: contamination sources, health effects and detection methods," International Journal of Environmental Research and Public Health, vol. 16, no. 22, p. 4361, 2019.

[5] J. R. Richardson, V. Fitsanakis, R. H. S. Westerink, and A. G. Kanthasamy, "Neurotoxicity of pesticides," Acta Neuropathologica, vol. 138, pp. 343-362, 2019.

[6] D. Luo, Y. Pu, H. Tian, W. Wu, and X. Sun, "Association of in utero exposure to organochlorine pesticides with thyroid hormone levels in cord blood of newborns," Environmental Pollution, vol. 231, pp. 78-86, 2017.

[7] A. Mokarizadeh, M. R. Faryabi, M. A. Rezvanfar, and M. Abdollahi, "A comprehensive review of pesticides and the immune dysregulation: mechanisms, evidence and consequences," Toxicology Mechanisms and Methods, vol. 25, pp. $258-278,2015$.

[8] C. A. Robledo, E. Yeung, P. Mendola, R. Sundaram, and J. Maisog, "Preconception maternal and paternal exposure to persistent organic pollutants and birth size," The LIFE Study, vol. 123, pp. 88-94, 2015.

[9] X. Xu, A. B. Dailey, E. O. Talbott, V. A. Ilacqua, G. Kearney, and N. R. Asal, "Associations of serum concentrations of organochlorine pesticides with breast cancer and prostate cancer in," U.S. Adults.vol. 118, pp. 60-66, 2010.

[10] M. Aamir, S. Khan, and G. Li, "Dietary exposure to HCH and DDT congeners and their associated cancer risk based on Pakistani food consumption," Environmental Science and Pollution Research, vol. 25, no. 9, pp. 8465-8474, 2018.

[11] J. Song, X. Gao, Y. Rong, D. Zhang, and H. Sui, "Mechanism for degradation of dichlorodiphenyltrichloroethane by mechano-chemical ball milling with Fe-Zn bimetal," Journal of Environmental Management, vol. 247, pp. 681-687, 2019.

[12] S. Al-Rashed, N. Marraiki, A. Syed et al., "Bioremediation characteristics, influencing factors of dichlorodiphenyltrichloroethane (DDT) removal by using non-indigenous Paracoccus sp," Chemosphere, vol. 270, Article ID 129474, 2021.

[13] F. E. Titchou, H. Zazou, H. Afanga, J. El Gaayda, R. A. Akbour, and M. Hamdani, "Removal of Persistent Organic Pollutants (POPs) from water and wastewater by adsorption and 
electrocoagulation process," Groundwater for Sustainable Development, vol. 13, Article ID 100575, 2021.

[14] M. F. M. Yusop, M. A. Ahmad, N. A. Rosli, F. N. Gonawan, and S. J. Abdullah, "Scavenging malachite green dye from aqueous solution using durian peel based activated carbon," Malaysian Journal of Fundamental and Applied Sciences, vol. 17, pp. 95-103, 2021 a.

[15] M. F. M. Yusop, M. A. Ahmad, N. A. Rosli, and M. E. A. Manaf, "Adsorption of cationic methylene blue dye using microwave-assisted activated carbon derived from acacia wood: optimization and batch studies," Arabian Journal of Chemistry, vol. 14, Article ID 103122, 2021 b.

[16] G. Ravenni, G. Cafaggi, Z. Sárossy, K. T. Rohde Nielsen, J. Ahrenfeldt, and U. B. Henriksen, "Waste chars from wood gasification and wastewater sludge pyrolysis compared to commercial activated carbon for the removal of cationic and anionic dyes from aqueous solution," Bioresource Technology Reports, vol. 10, Article ID 100421, 2020.

[17] A. Khasri and M. A. Ahmad, "Adsorption of basic and reactive dyes from aqueous solution onto Intsia bijuga sawdust-based activated carbon: batch and column study," Environmental Science and Pollution Research, vol. 25, pp. 31508-31519, 2018.

[18] M. F. M. Yusop, M. A. Ahmad, N. K. E. M. Yahaya et al., "Effect bed height on adsorption of $\mathrm{Cu}$ (II) by using corncob based activated carbon," Advances in Engineering Research, vol. 200, pp. 164-168, 2020.

[19] F. Zhang, S. Zhang, L. Chen, Z. Liu, and J. Qin, "Utilization of bark waste of Acacia mangium: the preparation of activated carbon and adsorption of phenolic wastewater," Industrial Crops and Products, vol. 160, Article ID 113157, 2021.

[20] A. Melliti, V. Srivastava, J. Kheriji, M. Sillanpää, and B. Hamrouni, "Date Palm Fiber as a novel precursor for porous activated carbon: optimization, characterization and its application as Tylosin antibiotic scavenger from aqueous solution," Surfaces and Interfaces, vol. 24, Article ID 101047, 2021.

[21] L. R. Conde-Rivera, A. F. Suarez-Escobar, J. J. Marin-Perez, M. J. Junco-Rodriguez, and F. E. Lopez-Suarez, "TiO2 supported on activated carbon from tire waste for ibuprofen removal," Materials Letters, vol. 291, Article ID 129590, 2021.

[22] J. Serafin, M. Ouzzine, O. F. Cruz Junior, and J. SreńscekNazzal, "Preparation of low-cost activated carbons from amazonian nutshells for CO2 storage," Biomass and Bioenergy, vol. 144, Article ID 105925, 2021.

[23] S. Wang, H. Nam, and H. Nam, "Preparation of activated carbon from peanut shell with $\mathrm{KOH}$ activation and its application for H2S adsorption in confined space," Journal of Environmental Chemical Engineering, vol. 8, Article ID 103683, 2020.

[24] M. A. Ahmad, M. F. Mohamad Yusop, R. Zakaria et al., "Adsorption of methylene blue from aqueous solution by peanut shell based activated carbon," Materials Today: Proceedings, vol. 47, pp. 1246-1251, 2021.

[25] M. A. Ahmad, M. F. M. Yusop, and S. H. Tan, "Activated carbon from meranti wood sawdust waste prepared by microwave heating for dye removal," in Advances in Waste Processing Technology, A. Z. Yaser, Ed., Springer Nature Singapore Pte. Ltd, Singapore, 2020.

[26] M. A. Ahmad, M. Aswareusoff, P. O. Oladoye, K. A. Adegok, and O. S. Bell, "Optimization and batch studies on adsorption of methylene blue dye using pomegranate fruit peel based adsorbent," Chemical Data Collections, vol. 24, Article ID 100676, 2021.
[27] A. A. Ahmad, A. T. M. Din, N. K. E. Yahaya, A. Khasri, and M. A. Ahmad, "Adsorption of basic green 4 onto gasified Glyricidia sepium woodchip based activated carbon: optimization, characterization, batch and column study," Arabian Journal of Chemistry, vol. 13, no. 8, pp. 6887-6903, 2020a.

[28] M. F. M. Yusop, H. A. Aziz, and M. A. Ahmad, "Scavenging remazol brilliant blue $\mathrm{R}$ dye using microwave-assisted activated carbon from acacia sawdust: equilibrium and kinetics studies," AIP Conference Proceedings, vol. 1892, Article ID 040018, 2017.

[29] M. A. Ahmad, S. R. A. Hamid, M. F. M. Yusop, and H. A. Aziz, "Optimization of microwave-assisted durian seed based activated carbon preparation conditions for methylene blue removal," AIP Conference Proceedings, vol. 1892, pp. 1-11, 2017.

[30] R. Badrnezhad and B. Mirza, "Modeling and optimization of cross-flow ultrafiltration using hybrid neural network-genetic algorithm approach," Journal of Industrial and Engineering Chemistry, vol. 20, no. 2, pp. 528-543, 2014.

[31] I. Langmuir, "The adsorption of gases on plane surfaces of glass, mica and platinum," Journal of the American Chemical Society, vol. 40, no. 9, pp. 1361-1403, 1918.

[32] H. M. F. Freundlich, "Over the adsorption in solution," The Journal of Physical Chemistry, vol. 57, pp. 385-471, 1906.

[33] M. I. Temkin and V. Pyzhev, "Kinetics and ammonia synthesis on promoted iron catalyst," Acta Physiochimica USSR, vol. 12, pp. 327-356, 1940.

[34] S. Lagergren and K. Svenska, "About the theory of so-called adsorption of soluble substances," Kungliga Svenska Vetenskapsakademiens Handlingar, vol. 24, pp. 1-39, 1898.

[35] Y. S. Ho and G. Mckay, "Pseudo-second order model for sorption processes," Process Biochemistry, vol. 34, no. 5, pp. 451-465, 1999.

[36] R. K. Liew, E. Azwar, P. N. Y. Yek, and X. Y. Lim, "Microwave pyrolysis with $\mathrm{KOH} / \mathrm{NaOH}$ mixture activation: a new approach to produce micro-mesoporous activated carbon for textile dye adsorption," Bioresource Technology, vol. 266, pp. 1-10, 2018.

[37] H. Tounsadi, A. Khalidi, A. Machrouhi et al., "Highly efficient activated carbon from Glebionis coronaria L. biomass: optimization of preparation conditions and heavy metals removal using experimental design approach," Journal of Environmental Chemical Engineering, vol. 4, pp. 4549-4564, 2016.

[38] M. A. Islam, M. J. Ahmed, W. A. Khanday, M. Asif, and B. H. hameed, "Mesoporous activated carbon prepared from $\mathrm{NaOH}$ activation of rattan (Lacosperma secundiflorum) hydrochar for methylene blue removal," Ecotoxicology and Environmental Safety, vol. 138, pp. 279-285, 2017.

[39] L. Zhou, Q. Yu, Y. Cui et al., "Adsorption properties of activated carbon from reed with a high adsorption capacity," Ecological Engineering, vol. 102, pp. 443-450, 2017.

[40] V. Tharaneedhar, P. Senthil Kumar, A. Saravanan, C. Ravikumar, and V. Jaikumar, "Prediction and interpretation of adsorption parameters for the sequestration of methylene blue dye from aqueous solution using microwave assisted corncob activated carbon," Sustainable Materials and Technologies, vol. 11, pp. 1-11, 2017.

[41] S. Agarwal, V. K. Gupta, M. Ghasemi, and J. Azimi-Amin, "Peganum harmala -L Seeds adsorbent for the rapid removal of noxious brilliant green dyes from aqueous phase," Journal of Molecular Liquids, vol. 231, pp. 296-305, 2017.

[42] M. Danish, W. A. Khanday, R. Hashim, N. S. B. Sulaiman, M. N. Akhtar, and M. Nizami, "Application of optimized large 
surface area date stone ( Phoenix dactylifera ) activated carbon for rhodamin B removal from aqueous solution: box-Behnken design approach," Ecotoxicology and Environmental Safety, vol. 139, pp. 280-290, 2017.

[43] T. L. Silva, A. Ronix, O. Pezoti, L. S. Souza, and P. K. T. Leandro, "Mesoporous activated carbon from industrial laundry sewage sludge: adsorption studies of reactive dye Remazol Brilliant Blue R," Chemical Engineering Journal, vol. 303, pp. 467-476, 2016.

[44] R. Boussahel, H. Irinislimane, D. Harik, and K. M. Moussaoui, "Adsorption, kinetics, and equilibrium studies on removal of 4-DDT from aqueous solutions using low-cost adsorbents," Chemical Engineering Communications, vol. 196, no. 12, pp. 1547-1558, 2009.

[45] H. Tian, J. Li, Q. Shen et al., "Using shell-tunable mesoporous Fe3O4@HMS and magnetic separation to remove DDT from aqueous media," Journal of Hazardous Materials, vol. 171, pp. 459-464, 2009.

[46] M. R. Taha and S. Mobasser, "Adsorption of DDT and PCB by nanomaterials from residual soil," PLoS One, vol. 10, Article ID e0144071, 2015.

[47] M. Gebresemati and O. Sahu, "Sorption of DDT from synthetic aqueous solution by eucalyptus barkusing response surface methodology," Surfaces and Interfaces, vol. 1-3, pp. 35-43, 2016.

[48] S. H. Chen, F. L. Xu, R. Dawson, X. C. Jiao, and S. Tao, "Adsorption and absorption of dichlorodiphenyltrichloroethane (DDT) and metabolites (DDD and DDE) by rice roots," Environmental Pollution, vol. 147, no. 1, pp. 256-261, 2007.

[49] M. A. Islam, A. Benhouria, M. Asif, and B. H. Hameed, "Methylene blue adsorption on factory-rejected tea activated carbon prepared by conjunction of hydrothermal carbonization and sodium hydroxide activation processes," Journal of the Taiwan Institute of Chemical Engineers, vol. 52, pp. 57-64, 2015. 